\title{
Educação do corpo: apontamentos para a historicidade de uma noção
}

\section{Education of the body: notes for the historicity of a notion}

\author{
Carmen Lucia Soares*
}

\begin{abstract}
RESUMO
O texto parte da hipótese de que, em uma longa duração, uma educação do corpo é lentamente elaborada por diferentes sujeitos e instituições, com a finalidade de criar gestos comuns, usos comuns do corpo voltados ao cuidado de si, de sua aparência e, mais amplamente, da proteção de suas próprias forças. Trata-se, assim, de um tipo de educação que, neste tempo longo, produz, seja de forma silenciosa, seja de forma eloquente, conselhos, prescrições, normas voltadas ao corpo, constituindo, assim, processos educativos. O texto examina e analisa alguns desses processos educativos capturados em traços no conjunto de fontes constituído por textos religiosos, tratados de pintura, romance, tratados de boas maneiras e de civilidade produzidos entre o século XII e XVIII. Para os propósitos e o espaço deste texto, a breve análise realizada demonstra a existência de uma abundância de referências ao corpo e aos gestos nesses registros e constitui, sem dúvida, um bom ponto de partida para esboçar apontamentos acerca da historicidade da noção educação do corpo.
\end{abstract}

Palavras-chave: Educação do corpo. História do corpo. Educação.

\begin{abstract}
This paper assumes the hypothesis that an education of the body is produced, in the long-term, by different subjects and institutions for the purpose of creating common gestures and uses of the body, aiming at taking care of oneself, one's appearance and, moreover, the protection of one's strengths. In this sense, this education produces, in the long-term, advices, prescriptions, regulations on the body and, therefore, establishing educational processes.
\end{abstract}

*Universidade Estadual de Campinas, Campinas, São Paulo, Brasil. E-mail: carmenls@ unicamp.br - http://orcid.org/0000-0002-4347-1924 
This text examines and analyses some of these educational processes captured in a set of sources constituted by religious texts, treatises on painting, romances, treatises on good manners and civility produced between the $12^{\text {th }}$ and the $18^{\text {th }}$ centuries. The brief analysis presented here shows the existence of an abundance of references about the body and the gestures in these records, constituting undoubtedly an adequate starting point to outline notes on the historicity of the notion of education of the body.

Keywords: Education of the body. History of the body. Education.

\section{Em busca de fios...}

Educação do corpo é uma noção que se faz presente em pequenos traços, por vezes discretos, pouco visíveis, por vezes muito eloquentes. É o olhar atento que pode capturá-los, sobretudo, se esse olhar considerar a seguinte pergunta: como se educam os corpos em uma longa duração? ${ }^{1}$ Se partirmos da hipótese de que uma educação do corpo é, ao mesmo tempo, difusa e concentrada, espontânea e especializada, é esse quadro ambíguo, impreciso e extenso que merece atenção e exame. Ele é composto de detalhes que se encontram nos interstícios dos textos escritos por eruditos, religiosos, médicos; nos personagens dos romances; nos ângulos e nas sombras das pinturas; nos talhes das esculturas que arrancam do mármore, da pedra ou da madeira formas corporais modelares.

Assim, de forma difusa ou especializada e precisa, constata-se pouco a pouco a emergência de uma educação corporal ${ }^{2}$, compreendida como constitutiva de um quadro mais geral de preocupações públicas e de gestão social (CORBIN, 2005). Processos educativos massivos são postos em marcha muito antes e para além da instituição escolar, e inúmeros deles se processam em direção às manifestações corporais, às expressões físicas de gestos, movimentos e emoções, exigindo aprendizados adequados a cada ocasião, a cada atividade (DUERR, 1998; ELIAS, 1994; SANT'ANNA, 2011; THOMAS, 2003).

O lugar que estudos e pesquisas sobre as maneiras, as sensibilidades, a intimidade na pesquisa histórica tiveram no âmbito da Escola dos Annales, sem dúvida fez ecoar o nascimento de um novo objeto de estudos e pesquisa: o

1 Trabalho aqui com a categoria de longa duração enunciada por Fernand Braudel (1969).

2 Essa temática vem sendo tratada no Brasil por inúmeros pesquisadores a partir de distintas referências teóricas e com significados também distintos. Ver, entre outros, Bassani e Vaz (2003), Soares (1998, 2014), Taborda de Oliveira e Linhales (2011), Taborda de Oliveira e Vaz (2004), Vaz (2003) e Vaz e Bombassaro (2012). 
corpo, ou, mais precisamente, suas práticas e representações (BLOCH, 1987; CORBIN; COURTINE; VIGARELLO, 2005; DUERR, 1998; ELIAS, 1994; FEBVRE, 1962; HAROUCHE, 2008; LE GOFF; TRUONG, 2003; LÉVISTRAUSS, 2003; MAUSS, 2003; SCHMITT, 1990; VIGARELLO, 1978, 2014). Assim, para tomar esse novo objeto, a educação necessita ser pensada a partir de outras referências e, sobretudo, ampliada em termos de seu alcance. Ela necessita ir além da instituição escolar e, assim, ser exercida por diferentes instituições e sujeitos. Ela, então, pode ser concebida como expressão de amplos processos culturais constituidos a partir do “ [...] conhecimento e prática dos usos e costumes de uma sociedade, tendo como finalidade introduzir indivíduos e grupos em distintas esferas da vida pública [...]" (SOARES, 2014, p. 219).

Pouco a pouco, e a partir desses fios soltos no tempo, foi possível tomar uma acepção de educação que confere atenção especial aos gestos, aos comportamentos cuja expressão se inscreve no corpo $^{3}$; ela seria, então, constituída pelas infinitas criações e recriações de processos educativos amplos, desenhados para tornar o corpo expressão de civilização. Efetivamente, tecer os fios dessa noção pode indicar, de um lado, delimitações mais precisas dos objetos a serem investigados e, de outro, a ampliação e a problematização da educação para além da instituição escolar.

Se a anatomia (MANDRESSI, 2003; SOARES; TERRA 2007; TERRA; SOARES, 2014) ocupou-se da materialidade do corpo sem vida, portanto, sem movimento, a educação tomará tanto sua dimensão física, fisiológica quanto suas formas de expressão, pois é do corpo vivo que essa educação tão ampla e ao mesmo tempo tão específica se ocupará. Tudo o que concerne ao corpo, desde a intimidade de sua fisiologia, até sentimentos e emoções será, pouco a pouco, demarcado pela cultura em suas singularidades, tornando-se objeto de uma educação cada vez mais específica. Processos educativos inéditos voltados ao corpo não cessaram mais de se aprimorar.

Este texto examina alguns desses processos educativos capturados em traços no conjunto de fontes que segue: a) Hugues de Saint-Victor, "De institutione novitiorum" (século XII); b) Thomas d'Aquin, "Somme théologique" (século XIII); c) "Decor Puellarun" (1471); d) Leon Batiste Alberti, "Tratado de Pintura" (século XV); e) Leonardo da Vinci, "Tratado de Pintura" (século $\mathrm{XV})$; f) Erasmo de Roterdam, "A Civilidade Pueril" (século XVI); g) François Rabelais, "Gargantua" (século XVI); h) Antoine de Courtin, "Nouveau Traité de la civilité qui se pratique en France parmi les honnestes gens" (século XVIII).

3 Em texto clássico de Marcel Mauss (2003, p. 405, itálico do autor), “As técnicas do corpo", "a palavra educação surge da maneira ampla e podemos ler que [...] da arte de utilizar o próprio corpo humano os fatos de educação predominavam. A noção de educação podia sobrepor-se à de imitação". 
O escrutínio dessas fontes permitiu a configuração inicial de uma cartografia de gestos e comportamentos, bem como de apontamentos do que se poderia denominar de processos educativos que tem no corpo sua ancoragem em uma longa duração. Dois conceitos são cruciais, no interior desses amplos processos educativos, para desenvolver nosso raciocínio acerca da noção educação do corpo: civilidade e cortesia. Se a civilidade era considerada como uma norma moral, competindo a todos preencher um papel educativo tanto no plano da regulação social quanto naquele da higiene física ou da perseverança moral, a cortesia era a demonstração de distintas convenções sociais, conforme lugares e épocas (ELIAS, 1994; MARGOLIN, 1994; PICARD, 1995; REVEL, 1991; ROUSSEL, 1995; THOMAS, 2003, 2014).

Esses conceitos são importantes, pois eles balizam todo um percurso de pedagogias e técnicas voltadas ao corpo individual e social, presentes em textos medievais de natureza religiosa que, pouco a pouco, passam a influenciar uma literatura didática e cortesã própria ao universo laico. Bastante prescritiva, essa literatura vai tomar os gestos e um controle mais amplo de si como centrais para estabelecer bases das inúmeras sociabilidades no Ocidente. O corpo é o lugar em que civilidade e cortesia se inscrevem, ele deve demonstrar expressão harmoniosa, ordenada e bela. Essa literatura didática tem a ambição de catalogar aquilo que - se supõe - diz respeito aos usos do corpo e aos comportamentos dos indivíduos em sociedade; e de compilar pedagogias que vão modificar o que se acredita que deva ser mudado (DUERR, 1998; ELIAS, 1994; THOMAS, 2003). Lentamente, se estrutura em diferentes âmbitos da sociedade, o que aqui denominamos de processos educativos voltados ao corpo.

\section{Gestos, comportamentos: sobre processos educativos voltados ao corpo}

Ao aludir a processos educativos amplos, desejamos assinalar a existência de algum tipo de organização em que conselhos e prescrições são divulgados, de certo modo assimilados e relativamente postos em prática. Os gestos ali tomam lugar central e são compreendidos como auxiliares no ordenamento das sociedades - desde aqueles mais solenes até os mais ordinários, inconscientes, repetitivos e comuns da vida de todos os dias, ao serem observados, possibilitam ao "[...] historiador penetrar no funcionamento mais profundo de uma sociedade [...]" (SCHMITT, 1990, p. 20).

$\mathrm{Na}$ longa duração que extrapola a Idade Média, afirma o autor que 
[...] os gestos devem expressar realidades ocultas, o interior da pessoa ("a alma", seus vícios e suas virtudes), enquanto que inversamente, "a disciplina" dos gestos, corresponde ao exterior do corpo, e pode contribuir a reformar o homem interior. De onde, também, face aos gestos, a atenção privilegiada que é dada as partes julgadas as mais "expressivas" do corpo: o rosto e o olhar [...] e as mãos que parecem "falar" (SCHMITT, 1990, p. 26, grifos do autor).

Essas "mãos que parecem falar", essa "expressão de realidades ocultas" que o corpo tão bem traduz e que necessita ser ordenada, compõem amplos processos educativos nos quais repousam as ambições de conhecer e de produzir formas cada vez mais específicas e especializadas de educar os corpos. Estaríamos diante de uma regulação e administração das distâncias e proximidades entre corpos e objetos no espaço, de deveres e obrigações, de deferências para retraçar continuidades. Como escreveu Claudine Harouche (2008, p. 51-52, grifos da autora),

[...] os gestos no fundamento das instituições conduzem a retomar vínculos negligenciados, esquecidos, a restabelecer certa continuidade entre a gesta - epopeia, narrativa, história - e, os gestos, condutas corporais, individuais de cada um. É necessário considerar os gestos que estruturam, simbolizam, materializam, ilustram a gesta como elementos fundadores de instituições jurídicas e políticas; e tentar então, discernir e precisar o papel das posturas, das atitudes, dos movimentos nos modelos de comportamento coletivo, nos sistemas institucionais [...].

Os gestos serão objeto de textos escritos por clérigos da Idade Média ${ }^{4}$, essa literatura prescritiva, detalhada e abrangente que será retomada em períodos posteriores e servirá de base para uma educação do corpo mais ampla, que alcançará a sociedade leiga. Essas obras traduzem uma necessidade de acordar gestos, condutas e comportamentos comuns, sistemas comuns aos que pretendiam viver em proximidade (THOMAS, 2003, 2014). Um ideal de cortesia

4 Esses clérigos medievais se apoiavam em textos antigos, tomando aspectos de obras de Horácio, Cicero e Sêneca, em que a modéstia se faz presente, dando direção a uma compreensão do corpo e dos comportamentos (LE GOFF, 1994; SCHMITT, 1990). A modéstia era definida como "[...] a virtude que sustenta as maneiras, cada movimento e nossa atividade para além da falta e para aquém do excesso [...]” (SCHMITT, 1990, p. 173). 
que preconiza uma vida social harmoniosa entre seus semelhantes expande-se e aprofunda-se, servindo ainda de referência para séculos posteriores. Trata-se de um tipo de conhecimento que repousa sobre valores como a amabilidade, a modéstia, a distinção, o asseio, a moderação, a sobriedade, o comedimento, o senso de justiça, constituindo-se em um ritual que envolve de modo profundo os indivíduos e estrutura suas relações (DUBY, 1984; LE GOFF, 1990, 1994; THOMAS, 2003, 2014).

Por volta do século XII, uma pedagogia dos gestos ocupa lugar de destaque e surge um novo gênero de literatura da Igreja: "as instruções", ou, "as instituições aos noviços". Conforme as análises de Schmitt (1990), a obra teórica de maior importância acerca dos gestos, naquele século é $A$ instituição aos noviços, de Hugues Saint Victeur, escrita em torno do ano de 1140. Em suas páginas encontrase uma infinidade de conselhos, recomendações e referências específicas ao corpo e são assinaladas preocupações com a falta de delicadeza dos monges, sobretudo com a "[...] a anarquia de seu espírito por meio da agitação e da desordem febril de membros de seu corpo [...]" (HUGUES DE SAINT-VICTOR, 1997, p. 49). Daí ser necessário o cultivo da disciplina considerada como "[...] um movimento ordenado de todos os membros e uma disposição decente de todo o corpo, seja em relação à sua postura, seja em relação as suas ações".

Outra obra escrita pouco depois de um século retoma as mesmas premissas. Trata-se da "Suma Teológica", escrita por Tomas de Aquino entre 1265 e 1273, em cujas páginas lemos o que deve primar no que se refere ao corpo, ou seja, a

[...] modéstia nos movimentos exteriores do corpo [...] a virtude moral consiste a ordenar pela razão tudo aquilo que é humano. Ora é claro que os movimentos exteriores do homem podem ser ordenados pela razão, pois os membros exteriores se movem ao comando da razão [...] (THOMAS D'AQUIN, 1970, p. 304) 5 .

Compõem esse conjunto de gestos e movimentos do corpo a serem aprendidos e incorporados, os comportamentos à mesa. Na obra de Huges Saint Victeur (1997, p. 49) aqui já citada, eles estão detalhados entre os capítulos 18 e 23, e recortados aqui em alguns extratos que seguem: “[...] não se servir do prato com as mãos [...] não se deve colocar seu dedo dentro do copo [...] É uma singular inconveniência vagabundear os olhos e olhar ao redor com curiosidade e, melhor dizendo, imprudentemente”. 
Os singelos atos de beber e comer - sem dúvida, atos biológicos, mas também sociais e culturais - revelam o surgimento e a incorporação lenta de normas por indivíduos e grupos (THOMAS, 2011). Foi assim que Jacques Le Goff (1965, p. 439), ao se referir a uma "civilidade medieval", assinalou que os gestos e os comportamentos à mesa eram uma dimensão central nestes processos civilizatórios, sendo a "[...] alimentação [...] a primeira ocasião para as classes dominantes da sociedade de manifestar sua superioridade neste domínio essencial da aparência [...]". Esses gestos à mesa demonstravam um domínio sobre o corpo e um combate a toda rusticidade presente nas expressões físicas; como extensão, incorporavam-se novos gestos de cortesia, como, por exemplo, aquele de lavar as mãos com água clara e perfumada. "[...] No fim do século $\mathrm{XII}$, as posturas à mesa enfatizam a necessidade da limpeza e podemos ler em diferentes textos a seguinte frase: 'Lave tuas mãos antes de jantar e quando tomar sua sopa [...]"” (THOMAS, 2011, p.74). Não há ainda, neste período, uma relação deste pequeno gesto com saúde, doença, ou mesmo prevenção; pensava-se ali na cortesia, em certa atitude polida que compunha essa educação e que implicava em um comportamento público acordado com o seu próximo; eram as expressões físicas que deveriam ser modificadas.

O conjunto desses novos gestos e comportamentos que marcavam distinção, encontrados nas recomendações que floresciam no interior dos monastérios medievais, alcançou, em seguida, as elites letradas e urbanas e se inscreveu nas linhas e entrelinhas de obras de períodos subsequentes; nelas, novos gestos aprendidos, acordados e ritualizados, acentuavam a necessidade da distância entre os indivíduos e, ainda, o uso de certos objetos na vida quotidiana, como o lenço para o ranho, ou os talheres, que pouco a pouco vão substituir os dedos. Lentamente o indivíduo interioriza a noção de que tocar na comida pode ser repugnante aos olhos dos outros (ELIAS, 1994; MARTIN; DUMOULIN; THELAMON, 1992; THOMAS, 2003).

A civilidade que cresce e se afirma no Renascimento bebe das fontes dessa "civilidade medieval" a que se referiu Le Goff; essa literatura didática, moral e ligada à cortesia prepara, em certa medida, as grandes obras acerca do tema do Renascimento simbolizadas por textos clássicos, como, entre outros ${ }^{7}$, "A civilidade pueril", de Erasmo de Roterdam (1978). O sucesso dessa obra

6 Jacques Le Goff (1965) tende a rever a periodização dos processos civilizatórios, estabelecida por Elias (1994), para quem seria o Renascimento o período central. Para Le Goff, ao lado de outros medievalistas, esse processo fora iniciado quatro séculos antes. Sobre o assunto ver também Thomas, 2011.

7 Duas obras podem ser aqui destacadas no período: "O cortesão", de Baldassare Castiglione, de 1528, e "O Galateo", de Giovanni dela Casa, de 1558. 
publicada em 1530 aproxima por muito tempo civilidade e boas maneiras, seu conteúdo traduz certa continuidade dessa literatura prescritiva que floresceu nos monastérios. Erasmo coloca em primeiro lugar os comportamentos de ordem física, tais como conter-se à mesa, assoar o nariz, cuspir, escarrar, modos de olhar e de caminhar. No pequeno extrato que segue, podemos ler que

[...] convém, portanto, que um homem preste atenção à sua aparência, aos seus gestos e à sua maneira de vestir, tanto quanto à sua inteligência. Não fica bem a uma criança bem educada agitar os braços, gesticular com os dedos, mexer os pés ou falar demais com o corpo do que com a língua; resumindo, uma criança deve ter o mesmo decoro ao jogo que à mesa $[\ldots]$ o passo não deve ser nem demasiado lento nem demasiado apressado - o primeiro é próprio de um insolente, e o segundo de um descabelado. [...] (ROTERDAM, 1978, p. 70-105).

Para Erasmo, enfim, “[...] educar o seu corpo, administrar seus gestos é tão importante quanto conhecer as belas letras [...] o gesto torna-se um discurso em si [...] a atitude do corpo permite[...] julgar as atitudes da alma" (BARRALBARON, 2015, p. 5-13). Traços dessas ideias acerca de uma administração geral do corpo e dos gestos tão didaticamente apresentadas por Erasmo aparecem em outras obras do período, como, por exemplo, no romance "Gargantua", escrito pelo médico e literato François Rabelais (1986), em 1543.

Em suas páginas encontramos prescrições acerca da necessidade de transformar a natureza rebelde de seu gigante, ensinando-o a dominar a gula, a ser comedido em seus gestos e em suas ações, a incorporar elementos de uma higiene em construção, indicando a lavagem das mãos, da boca e do rosto às refeições e o banho em água fria após os exercícios físicos. Trata-se aqui de sua segunda educação, em que predomina um equilíbrio entre atividades intelectuais, físicas e morais, e o corpo do gigante deve expressar os traços de civilidade e cortesia, em que o decoro à mesa se impõe e gestos rudes e desarmoniosos são combatidos. Rabelais (1986), joga com a ambiguidade e com as diferenças de percepção em relação ao corpo, presentes nesse tempo e descritas nessa tradição literária de gigantes como seres que ensinam regras de convivência, de alegria e de prazer carnal. Gargantua escolástico e Gargantua humanista convivem no romance e revelam as pedagogias e as políticas em voga.

Em uma linha de ruptura, mas também de continuidade, encontramos, no século XVIII, um gênero de literatura bastante divulgado: os tratados de civilidade. Eles se nutrem tanto da chamada civilidade medieval quanto do 
humanismo do Renascimento. O "Nouveau traité de civilité qui se pratique en France parmi les honnêtes gens", de Antoine de Courtin (1728) traz as seguintes recomendações:

[...] Quando estiveres à mesa não se deve assuar o nariz a não ser com o seu próprio lenço escondendo o máximo possível essa ação [...] não se deve jamais [...] arrotar e escarrar [...] Todas essas ações são indecências que revoltam todos a sua volta. [...] É absolutamente incivilizado limpar os dentes diante de todo mundo [...] (COURTIN, 1728, p. 206-217).

No mesmo tratado lemos alguns extratos sobre o controle mais amplo do corpo, quando se está em público: “[...] não se deve, jamais, fazer grandes gestos com as mãos no momento em que falamos; isto expressa bem aqueles que nada tem a dizer [...]" (COURTIN, 1728, p. 118). Vemos aqui traços nítidos do que escreveu Erasmo em 1530, quando argumentava a favor da contenção do corpo e dos gestos: "[...] sentada, é necessário que a criança mantenha os joelhos apertados, tal como os pés e não afastados, porque isso não é próprio. [...] sentada, a criança não deve agitar os braços, como os loucos, nem mexer impacientemente as mãos [...]" (ROTERDAM, 1978, p. 37- 80).

Trata-se de recomendações que permanecem em um longo período e são encontradas em outros gêneros de textos também bastante elucidativos de uma atenção ao corpo: os tratados de pintura e outros destinados à educação das jovens, em que há traços das muitas orientações presentes em textos religiosos, no que se refere aos gestos e sua tradução dos estados da alma, de sentimentos e emoções. Em suas páginas há indicações precisas de gestos, comportamentos, posturas, vestimentas, cores e movimentos do corpo considerados convenientes e outros a serem condenados.

Como assinalou Schmitt (1990, p. 46), “[...] os gestos são igualmente necessários à comunicação. Se uma pintura, imóvel, nos emociona, a mais forte razão são os gestos, porque eles [...] exprimem os sentimentos e fazem compreender as ideias; eles permitem aos mudos de comunicar [...]" ou, como escreveu Le Goff (1990, p. 81), afirmando serem os gestos “[...] o código de identificação do status, da condição, do valor do cristão, tal como são os gestos que permitem identificar o herege, assim é pelos gestos que se reconhece também o leigo, o pio, o santo. [...]". É assim que o historiador de arte do Renascimento Michael Baxandal (1991), ao se debruçar sobre a pintura daquele período, afirma que a gestualidade de origem religiosa será, com mais frequência, utilizada como modelar para assuntos profanos. 
Tomamos aqui alguns extratos do tratado de pintura escrito por Alberti (1992, p. 114-119) ${ }^{8}$, no século XV, texto pródigo em recomendações desse gênero, em que a expressão física do mental e do espiritual surge como preocupação central do autor. Assim, ele indica aos pintores que "[...] os movimentos da alma são conhecidos pelos movimentos do corpo [...] Por isso é importante que os pintores conheçam os movimentos do corpo; [...] A pintura deve ter movimentos suaves e graciosos, convenientes ao que nela acontece".

Em outro texto do Renascimento, o "Tratado de pintura", de Leonardo da Vinci $(1827)^{9}$, há indicações precisas acerca de atitudes e movimentos do corpo a serem observadas pelos pintores. No que se refere às atitudes, ele indica que:

[...] Nos homens se colocam as atitudes respeitando sua idade ou dignidade, que variam segundo requer o sexo.

[...] As mulheres e as jovens nunca devem ser pintadas com as pernas descompostas ou demasiadamente abertas: porque isto revela audácia ou falta de pudor e estando juntas demonstram vergonha (DA VINCI, 1827, p. 98-115).

Podemos ler aqui um diálogo de convenções e acordos caros à vida pública, em que se condena todo excesso e se enaltecem gestos delicados, de recato e pudor, especialmente para as moças. Um século antes de Leonardo da Vinci, Alberti (1992, p. 118) assinalava que, na pintura, “[...] os movimentos e as poses das moças [deveriam] ser leves, cheios de simplicidade, [e que existisse] de preferência a doçura da alma que a galhardia [...]".

Recomendação semelhante é encontrada nas páginas do "Decor Puellarum", manual destinado às moças, escrito em Veneza em 1471. Podemos ler indicações claras para o uso das mãos no extrato que segue:

[...] seja o tato, isto é, o belo hábito de as mãos não tocarem nunca nenhuma parte do corpo, seja do seu próprio ou de outrem, a não ser por suma necessidade, com toda a honestidade que se pode ter; e assim,

81 . ed. [1435-1436].

9 Trata-se de um conjunto de textos que escreveu ao longo de sua vida e que foram reunidos e publicados pela primeira vez em 1651, muitos anos após sua morte. 
permanecendo e indo sempre com a mão direita sobre a esquerda no nível da cintura $[. .$.$] a vossa frente [. .$.$] com aquela graça que convém a todas$ as mulheres virtuosas. [...] (DECOR PUELLARUN, 1471, p. 52-53).

Esse é um gesto que se inscreve em inúmeras telas entre os séculos XIV e $\mathrm{XVI}^{10}$, pois expressava o que seguidamente cabia à vida em público e, muito particularmente, às mulheres: o recato e o comedimento expressos no corpo.

O historiador Peter Burke (2000), ao tratar da "linguagem do gesto no início da modernidade", retoma textos escritos entre os séculos XIV e XV, para se referir a uma longa tradição que recomendava às moças demonstrar sempre timidez e modéstia, caminhando em pequenos passos, sorrindo sem mostrar os dentes e, mais amplamente, demonstrando contenção " [...] no andar e no movimento do corpo; pois o vagar dos olhos, um andar apressado e um excessivo movimento das mãos não podem ser feitos sem a perda de dignidade [...]" (BURKE, 2000, p. 103-104).

O ritmo dos passos, a entonação da voz, o vagar dos olhos e os modos do olhar, o uso das mãos. Uma educação do corpo vai, pouco a pouco, sendo catalogada e, de certo modo, divulgada; nela se encontram contenção, moderação, modéstia, disciplina, mas também domínio de si, cortesia e amabilidade. Tratase de uma atenção aguda a gestos e atitudes as mais íntimas e as mais públicas, seja em relação ao próprio corpo, seja em relação ao corpo do outro. Conforme assinalou Philippe Ariès (1991), foi entre os séculos XVI e XVIII que essas novas atitudes se ampliaram, sendo o século XVIII o período em que se afirmaram de modo singular. Para Vigarello (2014, p. 33, p. 27), no século XVIII ${ }^{11}$

[...] O corpo é, perante tudo, senão exclusivamente, relação com o mundo. Ele é o lugar em que se comprovam as coisas, comunicando-se com elas, medindo-as, avaliando-as.

[...] com o advento das Luzes, o indivíduo, pela primeira vez, comprova sua existência circunscrita ao espaço do seu corpo [...]".

10 Entre outras, as telas "Mona Lisa", de Leonardo da Vinci (1503), e "Retrato das três princesas da Saxônia", de Lucas Cranach (c.1535), em que as personagens sorriem sem mostrar os dentes e dispõem as mãos próximas à cintura, uma sobre a outra, gestos considerados modelares e adequados às mulheres, tal qual o indicavam os tratados de pintura e manuais para moças que citamos neste texto.

11 Corbin (2001) assinala que o corpo, neste século XVIII, torna-se uma central de escuta de emoções. 


\section{Entre gestos e movimentos, a educação do corpo se especializa}

Seria possível inferir que, no extenso e complexo escopo de ideias e ideais elaborados no século XVIII, contatava-se a ampliação de processos educativos inéditos voltados ao corpo; começava a se impor uma compreensão de que a imobilidade implica em fragilidade física, ausência de vigor e de saúde. Procedimentos, técnicas, pedagogias tomavam o movimento corporal como objeto privilegiado ${ }^{12}$; mas predominava ainda a ortopedia, com suas concepções e ações voltadas a um corpo imóvel através de arcabouços externos, como espartilhos e diversificados aparelhos que corrigiam supostos desvios da natureza inscritos no corpo. A imobilidade permanecia (SOARES, 2016; VIGARELLO, 1978, 2000).

Contudo, no âmbito mesmo da ortopedia, tão central naquele período, encontravam-se traços de mudança e de crítica à imobilidade e tinha lugar uma compreensão inédita de que o movimento poderia corrigir o que a "natureza" inscrevera no corpo. Andry de Boisregard (1741), ortopedista e médico, aposta na ação corporal, e não em sua passividade. Ele começa a compreender a potência muscular na correção e abre caminho para ideias acerca de um movimento que corrige. Essas ideias contribuíram para que o exercício físico fosse nivelado a aparelhos de correção e, ao mesmo tempo, para uma clareza em relação à existência de duas categorias de movimento: aqueles que corrigem e aqueles que educam (SOARES, 2016; VIGARELLO, 2000).

Uma literatura pedagógica mais específica voltada ao corpo se fez presente na segunda metade do século XVIII (VIGARELLO, 1978) e ela desejava fazer face à degenerescência física da população europeia que nesse período se mostrava devastadora. Se a constatação de que a imobilidade fragiliza já era aceita, caberia então buscar procedimentos e prescrições para regenerar, restaurar e, sobretudo, educar os corpos dessa população. E, se os exercícios corporais já eram nivelados aos "aparelhos" que corrigem no corpo os desvios da natureza, eles poderiam agora, sob a forma de Ginástica e ao lado de novas e inéditas práticas de higiene, fazer face à degenerescência física. Eles faziam parte da base de ideias de prevenção, de regeneração e de cura.

12 A obra de Jean-Jacques Rousseau pode ser aqui referida; ele se aliou aos médicos no combate aos espartilhos e à artificialidade da vestimenta e dos comportamentos de corte do período, exortando a uma educação que considerasse jogos e exercícios físicos ao ar livre; ver, especialmente, Rocha (2009); Rousseau (1976),1. ed. [1755]; Rousseau (1992), 1. ed. [1755]; Vigarello (1978); Vigarello (1993). 
Seria oportuno sublinhar, ainda, a importância de medidas higiênicas e de saneamento e seu impacto na intensa queda da mortalidade observada em países europeus no período incidindo na contenção de doenças, epidemias e do grande índice de mortalidade (BOURDELAIS, 2001; FOUCAULT, 2008; GONDRA, 2004; ROCHA, 2003).

Ao lado de tratados de boas maneiras e de cortesia floresciam, assim, aqueles que tinham na higiene seu conteúdo central; o lento percurso de práticas higiênicas em uma longa duração, suas modificações e a incorporação de aspectos morais e sanitários em seus procedimentos expressam, nitidamente, processos educativos voltados ao corpo. Desde a segunda metade do século XVIII a higiene passou a figurar em manuais de boas maneiras, cortesia, etiqueta; novas e inéditas representações do corpo e de sua educação são produzidas (DUERR, 1998; ELIAS, 1994; THOMAS, 2003; VIGARELLO, 1978, 1985, 2002).

Entre a afirmação de que a limpeza contribui para o vigor do corpo e para a prevenção da saúde, e não é apenas expressão de polidez e cortesia, próprias a outros períodos, os protocolos e as convenções da higiene desde o século XVIII não cessaram de se alargar, ao lado da ênfase à necessidade de exercícios físicos, ginásticas, jogos ao ar livre e esporte. A Ginástica é mencionada timidamente nesse período: revelam-se passeios ao ar livre, cavalgadas, jogos diversos, banhos de rio e de mar, danças que têm seu lugar para se evocar um corpo em movimento. Conforme sublinha Vigarello (2000, p. 74), “[...] as Luzes pretendem dar aos exercícios físicos a mesma amplitude revolucionária dada ao saber: a de torná-lo educativo e útil para todos".

Aqui há uma ruptura fundamental, no que concerne à elaboração de processos educativos mais sofisticados e especializados voltados ao corpo, pois as aprendizagens não seriam mais aquelas correlatas aos gestos de cortesia e civilidade, as etiquetas. Tratava-se, naquele momento, de desenvolver uma eficácia global do corpo em sua nova representação, qual seja, um corpo vigoroso, firme e ativo. Assim, “[...] na metade do século XVIII [...] se inventam uma 'educação física', 'educação corporal', 'educação medicinal'. Expressões e projetos inéditos renovando a velha tradição higiênica [...]" (VIGARELLO, 2000, p. 74). Inaugura-se, com singularidade, o lugar dos exercícios fisicos na educação dos indivíduos, não mais apenas como correção ou controle do corpo (SOARES, 2016; VIGARELLO, 2000). Gestos, atitudes e movimentos tanto no mundo do trabalho quanto naquele dos divertimentos são descritos detalhadamente e aparecem em manuais ${ }^{13}$, os mais diversos.

13 Como é o caso do manual de jogos publicado por Guts Muths (1959), em 1796, cujo conteúdo aborda jogos voltados a exercícios de recuperação do corpo e do espírito, conforme indicam os estudos de Quitzau (2016). 
[...] Uma nova mentalidade se cria, uma nova maneira de lidar com o corpo em movimento se afirma, criando, assim, um terreno fértil para o que é caro às Luzes [...] a difusão de saberes e práticas, a universalização de instrumentos, a afirmação científica de conhecimentos do e sobre o corpo em movimento (SOARES, 2016, p. 59).

A Ginástica, com seus métodos e técnicas, aparelhos e espetáculos, tornase uma forma específica de educação do corpo, conforme escreveu SOARES (1998), e faz emergir novos significados no âmbito mais geral da educação de indivíduos e grupos, para além da ortopedia, ainda em voga num período de grandes transformações, deslocamentos científicos, culturais e políticos que vão interferir na visão clássica do exercício corporal, em que as posturas testemunhavam o domínio das paixões (VIGARELLO, 1978).

Esse momento de rupturas profundas permitiu e assegurou uma educação corporal mais precisa, especializada. Dos métodos e escolas de ginástica (MORENO; BAIA, 2019; QUITZAU, 2016; SOARES, 1998) amplamente disseminados na Europa desde fins do século XVIII, de uma ginástica voltada à população em geral, antes mesmo de sua recomendação na instituição escolar, há uma vereda aberta para outras iniciativas na conformação de processos educativos específicos e especializados voltados ao corpo. Este foi bem o caso do esporte moderno na passagem do século XVIII para o século XIX. Entre a obrigação e o prazer, o esporte modernizou processos educativos e competiu com a ginástica na educação do corpo na cidade. Mais do que treinar o corpo e aprender a partir de uma disciplina mais rígida própria do mundo da ginástica, o esporte moderno trouxe a ambiguidade e a quase inconsciência de treinar o corpo brincando, conforme analisou Andre Rauch (1983).

Seria possível inferir que desde a segunda metade do século XVIII constata-se a emergência de uma nova sensibilidade, que amplia formas inéditas de educação do corpo, rompendo com antigas representações em que a imobilidade imperava. Novas formas de educação do corpo emergem, expandem-se e não cessam de se sofisticar. O movimento não apenas corrige, mas educa, regenera, preserva forças e aumenta o vigor dos corpos; é do corpo em movimento que trata a educação como processo amplo de inserção de indivíduos e grupos em distintas esferas da vida pública (RAUCH, 1983; SOARES, 2014, 2016; VIGARELLO, 1978, 2000). 


\section{Apontamentos... Quase finais}

Na longa duração, esse tempo lento, quase no limite da imobilidade, como escreveu Braudel (1969), permeado por rupturas e continuidades, diferentes registros se vão transformando e fazendo emergir processos educativos voltados ao corpo. Neste artigo examinamos, brevemente, alguns desses grandes processos a partir de um conjunto de obras e autores, cujo conteúdo desejou criar gestos comuns, regras para assimilar comportamentos comuns, usos comuns do corpo, induzindo indivíduos a cuidarem de si, de sua aparência, a se protegerem de suas próprias forças e, assim, contribuir para a vida em sociedade. Nosso recorte temporal termina num período de grandes rupturas, que foi o século XVIII, período no qual processos educativos inéditos voltados ao corpo têm lugar e em que gestos e movimentos são requeridos tanto no mundo dos divertimentos, quanto naquele das curas, da regeneração do corpo e, mais amplamente, de sua educação, concebida também como prevenção. Nos fios do tempo precariamente enredados, foi possível apreender traços da existência desses amplos processos educativos voltados ao corpo, seja no âmbito dos controles de sua fisiologia, lentamente aprendidos e singularmente vividos em diferentes sociedades e comunidades (DUERR, 1998; ELIAS, 1994), seja mesmo nas inúmeras representações que grupos, indivíduos e sociedades constroem de si mesmos. Esses processos, por vezes discretos, por vezes incisivos e eloquentes, alcançaram os corpos e corroboraram a criação de redes de sociabilidades, na produção de conhecimentos, de saberes e de práticas, assegurando e ordenando as relações entre as gerações (SOARES, 2014). Nosso propósito aqui foi evidenciar e examinar alguns desses processos colocados em marcha em diferentes esferas da vida individual e coletiva em uma longa duração, mesmo correndo o risco de incorrer em certas imprecisões.

Os breves apontamentos aqui esboçados acerca dessa noção-educação do corpo demonstram que se trata de um objeto fugidio e, ao mesmo tempo, de objetos que se dispersam, de problemáticas que se esfumaçam no tempo. Assim, as fontes aqui interrogadas e analisadas certamente responderam perguntas formuladas no tempo em que foram elaboradas, e elas não seriam as mesmas que poderíamos formular hoje. Contudo, encontrar a abundância de referências ao corpo e aos gestos nestes registros constitui, sem dúvida, um bom ponto de partida para esboçar apontamentos acerca da historicidade dessa noção. 


\section{REFERÊNCIAS}

ALBERTI, Leon Battista. Tratado de Pintura. 2. ed. Campinas: Editora Unicamp, 1992. ARIÈS, Philippe. Por uma história da vida privada. In: ARIÈS, Philippe; CHARTIER, Roger (org.). História da vida privada. Da Renascença ao século das Luzes. São Paulo: Companhia das Letras, 1991. v. 3, p. 7-19.

BARRAL-BARON, Marie. Érasme et l'art du geste: l'élaboration des règles de civilité à la Renaissance. Europa Moderna - Revue d'Histoire et d'Iconologie, Lyon, n. 5, p. 4-13, 2015. DOI: https://doi.org/10.3406/emod.2015.867. Disponível em: https:// www.persee.fr/doc/emod_2107-6642_2015_num_5_1_867. Acesso em: 13 jul. 2020.

BASSANI, Jaison José; VAZ, Alexandre Fernandez. Comentários sobre a educação do corpo nos textos pedagógicos de Theodor W. Adorno. Perspectiva, Florianópolis, v. 21, n. 1, p. 13-37, 2003.

BAXANDALL, Michael. O olhar renascente: pintura e experiência social na Itália da Renascença. Rio de Janeiro: Paz e Terra, 1991.

BLOCH, Marc. A história feudal. 2. ed. Lisboa: Edições 70, 1987.

BOISREGARD, Nicolas Andry de. L'Orthopédie ou L'Art de prevoir et de corriger dans les enfants les difformités du corps. Paris: Lambert \& Durnad, 1741. 2 v.

BOURDELAIS, Patrice (dir.). Les hygiènistes: enjeux, modèles et pratiques. Paris: Belin, 2001.

BRAUDEL, Fernand. Écrits sur l'histoire. Paris: Flammarion, 1969.

BURKE, Peter. Variedades de história cultural. Rio de Janeiro: Civilização Brasileira, 2000.

CORBIN, Alain. L'homme dans le paysage. Paris: Textuel, 2001.

CORBIN, Alain. Prefácio. In: CORBIN, Alain; COURTINE, Jean-Jacques; VIGARELLO, Georges. Histoire du corps. De la Révolution à la Grande Guerre. Paris: Seuil, 2005. v. 2.

CORBIN, Alain; COURTINE, Jean-Jacques; VIGARELLO, Georges. Prefácio. In: CORBIN, Alain; COURTINE, Jean-Jacques; VIGARELLO, Georges. Histoire du corps. De la Révolution à la Grande Guerre. Paris: Seuil, 2005. v. 1, p. 7- 15.

COURTIN, Antoine de. Nouveau traité de la civilité qui se pratique en France parmi les honnêtes gens. Paris: Louis Josse \& Charles Robustel, 1728.

DA VINCI, Leonardo. El tratado de la pintura... Tradução de Diego Antonio Rejón de Silva. Madrid: Imprenta Real, 1827. 
DECOR PUELLARUN. JENSON, Nicolas (ed.). Venice: [S.n.], 1471. Disponível em: https://archive.org/details/ita-bnc-in2-00002284-001/page/n10/mode/2up. Acesso em: 1 jun., 2020.

DUBY, Georges. L'Europe au Moyen Âge. Art Roman, art gothique. Paris: Flammarion, 1984.

DUERR, Hans Peter. Nudité \& pudeur: le mythe du processus de civilisation. Paris: Fondation Maison des Sciences de l'Homme, 1998.

ELIAS, Norbert. O processo civilizador: a história dos costumes. 2. ed. Rio de Janeiro: Zahar, 1994. v. 1.

FEBVRE, Lucien. Pour une histoire a part entière. Paris: SEVPEN, 1962.

FOUCAULT, Michel. Segurança, território, população. Curso dado no Collège de France (1977-1978). São Paulo: Martins Fontes, 2008.

GONDRA, José Gonçalves. Artes de civilizar: medicina, higiene e educação escolar na Corte Imperial. Rio de Janeiro: EDUERJ, 2004.

GUTS MUTHS, Johann Christoph Friedrich. Spiele zur Übung und Erholung des Körpers und Geistes. Berlin: Sportverlag, 1959.

HAROUCHE, Claudine. L'avenir du sensible. Les sens et les sentiments en question. Paris: PUF, 2008.

HUGUES DE SAINT-VICTOR. De institutione novitiorum...Texte latin par H. B. Feiss et P. Sicard, trad. française par D. Poirel. Turnhout: Brepols, 1997.

LE GOFF, Jacques. La civilisation de l'Occident medieval. Paris: Arthaud, 1965, p. 439.

LE GOFF, Jacques. O maravilhoso e o cotidiano no Ocidente Medieval. Lisboa: Edições $70,1990$.

LE GOFF, Jacques. Os intelectuais na Idade Media. 4. ed. São Paulo: Brasiliense, 1994.

LE GOFF, Jacques; TRUONG, Nicolas. Une histoire du corps au Moyen Âge. Paris: Editions Liana Levi, 2003.

LÉVI-STRAUSS, Claude. Prefácio à primeira edição. In : MAUSS, Marcel. Sociologia e Antropologia. São Paulo: Cosac Naify, 2003. p. 9-45.

MANDRESSI, Rafael. Le regard de l'anatomiste: Dissection et invention du corps en Occident. Paris: Seuil, 2003.

MARGOLIN, Jean-Claude. La civilité nouvelle. De la notion de civilité à sa pratique et aux traités de civilité. In: MONTANDON, Alain (dir.). Pour une histoire des traités de savoir-vivre en Europe. Clermond-Ferrand: Éditions InterUniversitaires, 1994. p. 151-177. 
MARTIN, Aurell; DUMOULIN, Olivier; THELAMON, Françoise (dir.). La sociabilité à table. Commensalité et convivialité à travers les âges: actes du Colloque de Rouen: avec la participation de Jacques Le Goff, 14-17 novembre 1990. Rouen : Université de Rouen, 1992.

MAUSS, Marcel. As técnicas do corpo. In: MAUSS, Marcel. Sociologia e Antropologia . São Paulo: Cosac Naify, 2003. p. 399- 422.

MORENO, Andrea; BAIA, Anderson da Cunha. Do Instituto Central de Ginástica (GCI) de Estocolmo para o Brasil: cultivo e divulgação de uma educação do corpo. Educação em Revista, Belo Horizonte, v. 35, e217636, 2019. Disponível em: https://www.scielo. br/scielo.php?script=sci_abstract\&pid=S0102-46982019000100805\&lng=pt\&nrm=iso \&tlng=pt. Acesso em: 30 ago. 2020.

PICARD, Dominique. Les rituels du savoir-vivre. Paris: Seuil, 1995.

QUITZAU, Evelise Amgarten. Associativismo ginástico e imigração alemã no Sul e Sudeste do Brasil (1858-1938). 2016. Tese (Doutorado em Educação) - Programa de Pós-Graduação em Educação, Unicamp, Campinas, 2016.

RABELAIS, François. Gargantua. Tradução de Aristides Lobo. São Paulo: HUCITEC, 1986.

RAUCH, André. Le souci du corps: l'hygiène en éducation physique. Paris: PUF, 1983.

REVEL, Jacques. Os usos da civilidade. In: ARIÈS, Philippe; DUBY, Georges. História da vida privada. Da Renascença ao Século das Luzes. São Paulo: Companhia da Letras, 1991. p. 169-209.

ROCHA, Heloísa Helena Pimenta. Entre a ortopedia e a civilidade: o higienismo e educação do corpo no Brasil. Separata. Historia de la Educación, Salamanca, España, n. 28 , p. $109-134,2009$.

ROCHA, Heloísa Helena Pimenta. A higienização dos costumes: educação escolar e saúde no projeto do Instituto de Hygiene de São Paulo. Campinas; São Paulo: Mercado de Letras; FAPESP, 2003. v. 1.

ROTERDAM, Erasmo de. A civilidade pueril. Lisboa: Estampa, 1978.

ROUSSEAU, Jean-Jacques. Discurso sobre a origem e fundamentos da desigualdade entre os homens. Lisboa: Europa América, 1976.

ROUSSEAU, Jean-Jacques. Emílio ou Da Educação. Rio de Janeiro: Bertrand Brasil, 1992.

ROUSSEL, Claude. Courtoisie. In: MONTANDON, Alain (dir.). Dictionnaire raisonné de la politesse et du savoir-vivre du Moyen Âge à nos jours. Paris: Seuil, 1995. p. 175-196.

SANT’ANNA, Denise Bernuzzi de. Higiene e higienismo entre o Império e a República. In: DEL PRIORE, Mary; AMANTINO, Marcia (org.). História do corpo no Brasil. São Paulo: Unesp, 2011. p. 283-312. 
SCHMITT, Jean-Jacques. La raison des gestes dans l'Occident Médiéval. Paris: Gallimard, 1990.

SOARES, Carmen Lucia. Imagens da educação no corpo: estudo a partir da ginástica francesa no século XIX. Campinas: Autores Associados, 1998.

SOARES, Carmen Lucia. Educação do corpo. In: GONZÁLES, Fernando Jaime; FENSTERSEIFER, Paulo Evaldo (org.). Dicionario crítico de Educação Fisica. 3. ed. Ijuí: Unijui, 2014. v. 1, p. 219-225.

SOARES, Carmen Lucia. A arte de aperfeiçoar a espécie humana: do exercício que corrige ao exercício que educa. In: CARVALHO, Yara Maria de; GOMES, Ivan M.; FRAGA, Alex Branco (org.). As práticas corporais no campo da saúde: pesquisa interinstitucional e a formação em rede. São Paulo: UCITEC, 2016. v. 1, p. 42-75.

SOARES, Carmen Lucia; TERRA, Vinicius Demarchi. Lições da Anatomia: geografias do olhar. In: SOARES, Carmen Lúcia. Pesquisas sobre o corpo, 2007. p. 101-116.

TABORDA DE OLIVEIRA, Marcus Aurelio; LINHALES, Meyli Asbú. Pensar a educação do corpo na e para a escola: indícios no debate educacional brasileiro (1882-1927). Revista Brasileira de Educação, Rio de Janeiro, v. 16, p. 389-407, 2011.

TABORDA DE OLIVEIRA, Marcus Aurélio; VAZ, Alexandre Fernandes. Educação do corpo: teoria e história. Perspectiva, Florianópolis, v. 22, p. 13-19, 2004. (Número Especial).

TERRA, Vinicius Demarchi; SOARES, Carmen Lucia. Anatomia e educação visual. In: MARQUETTI, Flávia Regina; FUNARI, Pedro Paulo Abreu (org.). Corpo a corpo: representações antigas e modernas da figura humana. São Paulo: FAP/UNIFESP, 2014. v. 1, p. 149-167.

THOMAS D’AQUIN. Somme théologique. La tempérance. IIa IIae q. 155-170, t. II, q. 168, art. 1. Tournai: Desclée \& Cie, 1970.

THOMAS, Jérôme. Corps violents, corps soumis. Le policement des moeurs à la fin du Moyen- Âge. Paris: L'Harmattan, 2003.

THOMAS, Jérôme. Et la civilité vint à table. L'Histoire, Paris: Sophia Publications, n. 363, p. 72- 75, 2011.

THOMAS, Jérôme. L'Évangélisation des populations andines au XVİ̀ siècle. Policía Cristiana et conquête des corps. Paris: Les Indes Savantes, 2014.

VAZ, Alexandre Fernandez. Educação do corpo, conhecimento, fronteiras. Revista Brasileira de Ciências do Esporte, Campinas, v. 24, n. 2, p. 161-172, 2003.

VAZ, Alexandre Fernandez; BOMBASSARO, Ticiane (org.). Fragmentos para uma história da educação do corpo em Santa Catarina. Florianópolis: DIOESC/FAPESC, 2012. 
VIGARELLO, Georges. Le corps redressé: histoire d'un pouvoir pédagogique. Paris: Jean-Pierre Delarge, 1978.

VIGARELLO, Georges. Le propre et la sale: l'hygiène du corps depuis le Moyen Âge. Paris: Seuil, 1985.

VIGARELLO, Georges. Le sain et le malsain: santé et mieux-être depuis le Moyen Âge. Paris: Seuil, 1993.

VIGARELLO, Georges. Passion Sport: histoire d'une culture. Paris: Textuel, 2000.

VIGARELLO, Georges. Du jeu ancien au show sportif: la naissance d'un mythe. Paris: Seuil, 2002.

VIGARELLO, Georges. Le sentiment de soi: histoire de la perception du corps. Paris: Seuil, 2014.

Texto recebido em 14/09/2020.

Texto aprovado em 18/11/2020. 